\title{
A Tiny Fabry-Perot Interferometer with Postpositional Filter for Measurement of the Thermospheric Wind
}

\author{
Houmao $\mathrm{WANG}^{1,2}$, Yongmei $\mathrm{WANG}^{1}$, and Jianguo $\mathrm{FU}^{1}$ \\ ${ }^{1}$ National Space Science Center, Chinese Academy of Sciences, Beijing, China \\ e-mails: hmwang@nssc.ac.cn (corresponding author),wym@nssc.ac.cn, \\ fujianguo@nssc.ac.cn \\ ${ }^{2}$ University of Chinese Academy of Sciences, Beijing, China
}

\begin{abstract}
A tiny and low-cost ground-based Fabry-Perot interferometer (FPI) was designed using a filter behind etalon and Galilean telescope system for the thermospheric wind observation with OI $630.0 \mathrm{~nm}$ nightglow emissions $(\sim 250 \mathrm{~km})$. Based on the instrument, experiments were carried out at Langfang $\left(39.40^{\circ} \mathrm{N}, 116.65^{\circ} \mathrm{E}\right)$ site for a rough comparison and Kelan $\left(38.71^{\circ} \mathrm{N}, 111.58^{\circ} \mathrm{E}\right)$ site for a detailed validation. Wind results of Langfang experiment are well consistent with measurements of two other FPIs deployed at Xinglong $\left(40.40^{\circ} \mathrm{N}, 117.59^{\circ} \mathrm{E}\right)$ and Kelan which are retrieved by the American National Center for Atmospheric Research (A-NCAR). In Kelan experiment, the averaged wind deviation between our FPI and A-NCAR FPI is $11.8 \mathrm{~m} / \mathrm{s}$. The averaged deviation of wind measurement error between them is $2.9 \mathrm{~m} / \mathrm{s}$. The comparisons suggest good agreement. Then, the analysis of influencing factors was made. The center determination offset has an exponential relation with wind deviation, while the radius calculation offset is linear with wind deviation.
\end{abstract}

Key words: Fabry-Perot interferometer (FPI), postpositional filter, thermospheric wind, $630.0 \mathrm{~nm}$ nightglow.

Ownership: Institute of Geophysics, Polish Academy of Sciences;

(C) 2016 Wang et al. This is an open access article distributed under the Creative Commons Attribution-NonCommercial-NoDerivs license,

http://creativecommons.org/licenses/by-nc-nd/3.0/. 


\section{INTRODUCTION}

The observations of thermosphere neutral winds are used for studying the dynamics and behavior of the thermospheric atmosphere and for developing forecasting capabilities for the space environment. The importance of measuring thermospheric winds is widely recognized in many research organizations' strategy, such as the latest NASA Heliophysics Roadmap (NASA 2009). However, the only technique that can probe thermospheric winds $(\sim 250 \mathrm{~km})$ from the ground is the passive optical technique, among which the Fabry-Perot interferometer is currently the leading instrument available for making wind measurements in this region.

To date, wind measurements using Fabry-Perot interferometers from the ground have been made for several decades by many scientists. Various investigations and improvements have been reported for FPIs, for example, studies featuring long-term measurements (Hernandez and Roble 1995, Biondi et al. 1999), use of cooled CCD detectors (Biondi et al. 1995, Shiokawa et al. 2001, 2003), two-dimensional imaging capability (Rees et al. 1984, Niciejewski et al. 1994, Nakajima et al. 1995, Ishii et al. 1997, Conde et al. 2001, Sakanoi et al. 2009, Kosch et al. 2010), and daytime measurement (Gerrard and Meriwether 2011, Wu et al. 2012). Most of these instruments are designed using large-aperture etalons and filters. Some FPIs have been reported using small-aperture etalons to lower the costs (Makela et al. 2009, 2011; Shiokawa et al. 2012).

In this paper, a new tiny and low-cost FPI instrument with a smaller post-filter is proposed for thermospheric wind retrieval using $630.0 \mathrm{~nm}$ airglow emission. Based on the instrument, wind measurements were made for several days in Langfang and Kelan. Therefore, the detailed information of the instrument is given in Section 2. The methodology for wind retrieval is presented in Section 3. In Section 4, the observed data and retrieval results are shown. Subsequently, sensitivity studies for wind retrieval of our FPI are presented in Section 5.

\section{INSTRUMENTATION}

Figure 1 shows the schematic diagram of prime optical system (a) and configuration (b) of our FPI. The sky scanner located above the optical system consists of two motors and two $45^{\circ}$ parallel mirrors for pointing the FPI optical axis toward any point of sky. The incident light passes through an etalon (fixed-gap spacing: $15 \mathrm{~mm}$, diameter: $130 \mathrm{~mm}$, reflectivity: 76\%), a Galilean telescope system, a band-pass filter (diameter: $70 \mathrm{~mm}$ ), a focus lens, and arrives at a $1024 \times 1024$ CCD detector (size: $13 \mathrm{~mm}$ ).

The instrument is mainly composed of four parts: (1) The front optics sky-scanner constructed with two mirrors has a field-of-view of $2.25^{\circ}$, in 
(a)

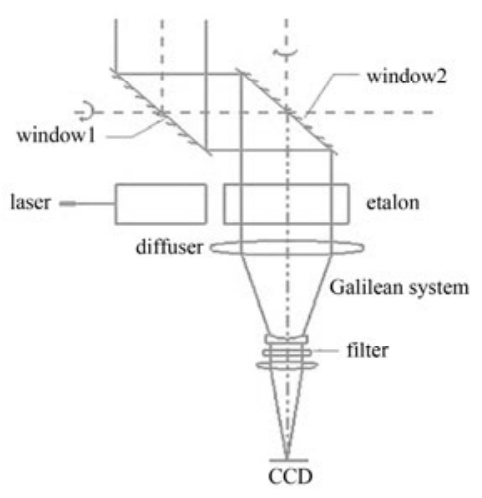

(b)

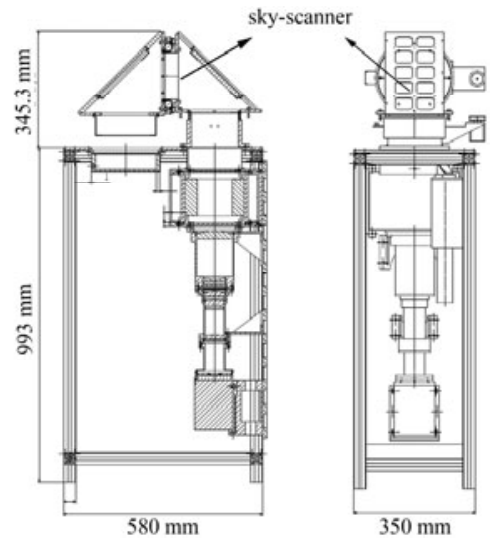

Fig. 1. The prime optical system with the filter behind etalon (a) and the corresponding configuration (b) of the Fabry-Perot (etalon fixed-gap spacing: $15 \mathrm{~mm}$, etalon diameter: $130 \mathrm{~mm}$, etalon reflectivity: $76 \%$, filter diameter: $70 \mathrm{~mm}$, CCD detector size: $13 \mathrm{~mm}$, FPI size: $1.34 \times 0.58 \times 0.35 \mathrm{~m}^{3}$ ).

which airglow emission can be assumed uniform. The diameter of the two mirrors is $10 \mathrm{~cm}$. One of the mirrors rotates to change the zenith, and the other is to change the azimuth. A cylinder hood and several stops are used in the first lens tube to prevent emissions out of field-of-view from entering instrument; (2) The etalon has a diameter of $130 \mathrm{~mm}$ with clear aperture of $100 \mathrm{~mm}$. It is mounted in a thermally isolated enclosure that is stabilized within $0.1{ }^{\circ} \mathrm{C}$ at $30^{\circ} \mathrm{C}$ for minimizing thermal drift; (3) The band-pass filter is fixed behind the etalon and Galilean telescope system to reduce the diameter to $70 \mathrm{~mm}$. This design is for saving the fabricating cost; (4) Finally, approximately seven full interference fringes are imaged using a focus lens $(f=$ $33.4 \mathrm{~cm})$ onto the CCD chip. The CCD is with low readout $(\sim 3 \mathrm{e} / \mathrm{pixel})$ and dark current $\left(\sim 0.0004 \mathrm{e} / \mathrm{sec} / \mathrm{pixel}\right.$ at a temperature of $\left.-70{ }^{\circ} \mathrm{C}\right)$. That allows for a long integration ( $\sim 5 \mathrm{~min})$ for analysis of the $630.0 \mathrm{~nm}$ emission. SParameters of other typical FPIs similar to our instrument are listed in Table 1.

All of these parts except for two sky-scanning mirrors are installed assembly in a box of $0.58 \times 0.35 \times 0.993 \mathrm{~m}^{3}$. Therefore, the tiny and compact instrument can be transported conveniently from one place to another using a car for wind observations.

The ground-based FPI measures the Doppler shift of the airglow emissions in a zenith direction and four azimuthal directions of eastward (E), westward (W), southward (S), and northward $(\mathrm{N})$ with a zenith angle of $45^{\circ}$ (Fig. 2). The FPI sky-scanner is sequentially steered to the five directions (Zenith, N, S, E, and W) to observe the OI $630.0 \mathrm{~nm}$ airglow emission with 
Table 1

The parameters of optical components of typical FPI

\begin{tabular}{|l|c|c|c|}
\hline \multicolumn{1}{|c|}{ FPI } & $\begin{array}{c}\text { Our instruments } \\
\text { Institute } \\
\text { Sational Space } \\
\text { China }\end{array}$ & $\begin{array}{c}\text { A-NCAR } \\
\text { National Center } \\
\text { for Atmospheric } \\
\text { Research, USA }\end{array}$ & $\begin{array}{c}\text { J-NU } \\
\text { Nagoya } \\
\text { University, } \\
\text { Japan }\end{array}$ \\
\hline Filter diameter/mm & 70 & - & $120 / 118.5$ \\
Etalon diameter/mm & 130 & 132 & 116 \\
Etalon fix-gap/mm & 15 & $15 / 20$ & 15 \\
Etalon reflectivity & $76 \%$ & $80 \%$ & $85 \%$ \\
CCD size/ $\mu \mathrm{m}$ & 13.312 & 13.312 & 13.312 \\
CCD pixel number & $1024 \times 1024$ & $1024 \times 1024$ & $1024 \times 1024$ \\
\hline
\end{tabular}

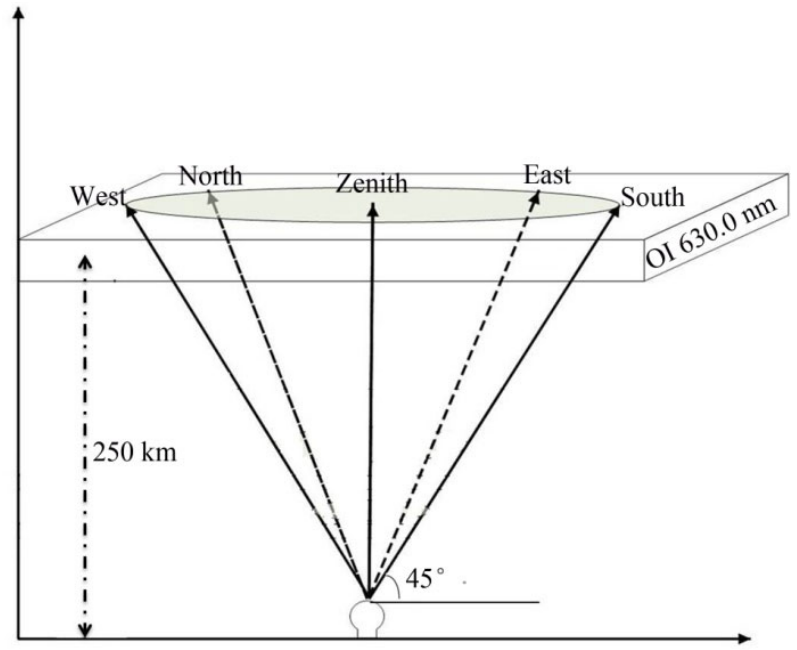

Fig. 2. The diagram of the ground-based Fabry-Perot observation with OI $630.0 \mathrm{~nm}$ airglow at $\sim 250 \mathrm{~km}$.

an exposure time of five minutes in each direction and $\sim 30 \mathrm{~min}$ for a cycle. At the beginning of night observation, the calibration is utilized with the skyscanner pointed towards a diffuser box uniformly illuminated by a HeNe frequency-stabilized laser. For acquirement of stable laser, calibrations are made five times sequentially.

\section{METHODOLOGY}

As the equal inclination interference formed by FPI, the interference order can be derived from the radius of fringe peak after series of transformations (Shiokawa et al. 2001): 


$$
m_{i}=\frac{2 \mu t}{\lambda_{0}\left(1-\frac{v}{c} \sin \theta\right)}\left(1-\frac{r_{i}^{2}}{2 f^{2}}\right),
$$

where $m$ is the interference order, subscript $i$ presents the number of fringe from the center to the edge, $\mu$ is the refractive index, $t$ is the etalon spacing, $\lambda_{0}$ is the central wavelength of the airglow without the Doppler shift, $r$ is the fringe peak radius in one observation direction, $f$ is the focal length, $c$ is the light speed, $\theta=45^{\circ}$ is the view zenith angle, and $v$ is horizontal wind velocity. Assuming that the vertical wind velocity was negligible and that the wind velocity was uniform between the two opposite directions (distance: $\sim 500 \mathrm{~km}$ ) holding in all areas except for high-latitude auroral zones (Smith 1998), zonal and meridional wind can be derived from the radiuses of eastward/westward and northward/southward fringe peaks, respectively. The equations are as follows:

$$
\begin{aligned}
& v_{N}=\frac{c}{\sin \theta} \frac{r_{S}^{2}-r_{N}^{2}}{4 f^{2}-\left(r_{S}^{2}+r_{N}^{2}\right)}, \\
& v_{E}=\frac{c}{\sin \theta} \frac{r_{W}^{2}-r_{E}^{2}}{4 f^{2}-\left(r_{E}^{2}+r_{W}^{2}\right)},
\end{aligned}
$$

where $r_{N}$ and $r_{S}$ are the radiuses of the northward and southward fringe peaks, respectively. $r_{E}$ and $r_{W}$ are the radiuses of the eastward and westward fringe peaks, respectively.

Based on Eqs. 2 and 3, wind velocity can be derived from the fringe radius. The details of procedure of data processing are provided in the literature (Wang and Wang 2015) and are briefly outlined here. First, we reduce noise using several filters to smooth out noise counts and neutralize background trend. Then, the fringe center is determined from the laser calibration image by fitting of a Gaussian function in horizontal and vertical cross sections (Kubota 1996). With the center determination, the fringe peak radius is determined using a Gaussian fitting based on annular-summed fringes. Finally, wind velocities are calculated from peak radius using Eqs. 2 and 3.

\section{OBSERVATION AND RESULTS}

Three observation sites in Xinglong, Langfang, and Kelan are used here for the validation of our FPI. The Langfang station is located to the east of Kelan with a linear distance of $\sim 440 \mathrm{~km}$ and to the south of Xinglong with a linear distance of $\sim 140 \mathrm{~km}$, so it is applicable to make a rough comparison of wind retrieval between them. Besides, measurements of two A-NCAR FPIs deployed at Xinglong and Kelan sites are considered as reference data. 
Therefore, two experiments were carried out for three days in Langfang in the end of September and for ten days in Kelan in the end of October in 2014.

Hampered by weather conditions, wind measurements of a clear night (24 September 2014) at Langfang site are compared with wind velocities of A-NCAR FPIs. The comparisons are shown in Fig. 3 that shows the wind velocity versus universal coordinated time (UTC) at Langfang, Xinglong, and Kelan sites. It suggests that our measurements at Langfang site are well consistent with wind variations at Xinglong and Kelan sites. However, due to weaker airglow emission at midnight, the retrieval errors become much larger with the largest values of $14 \mathrm{~m} / \mathrm{s}$ (Langfang), $34 \mathrm{~m} / \mathrm{s}$ (Kelan), and $18 \mathrm{~m} / \mathrm{s}$ (Xinglong) at $\sim 16: 30$ UTC (Fig. 3, error bar), and wind deviations between the three stations become larger during a period of 15:00 18:30 UTC. In Figure 3, it should be noted that the wind retrieval error of FPI at Langfang site is calculated from both the Gaussian fitting error of each fringe and the standard error of wind velocities (Wang and Wang 2015). It should be also noted that wind velocities are retrieved using 1 st-7th fringes.

For further validation, our FPI was subsequently deployed in Kelan on 16-26 October 2014 for a robust comparison with A-NCAR FPI. Due to the cold weather and the tiny shabby house, the temperature of our FPI is a little difficult to be controlled. Besides, there were some cloudy or rainy days during our experiment. Therefore, wind measurements of five nights are obtained.
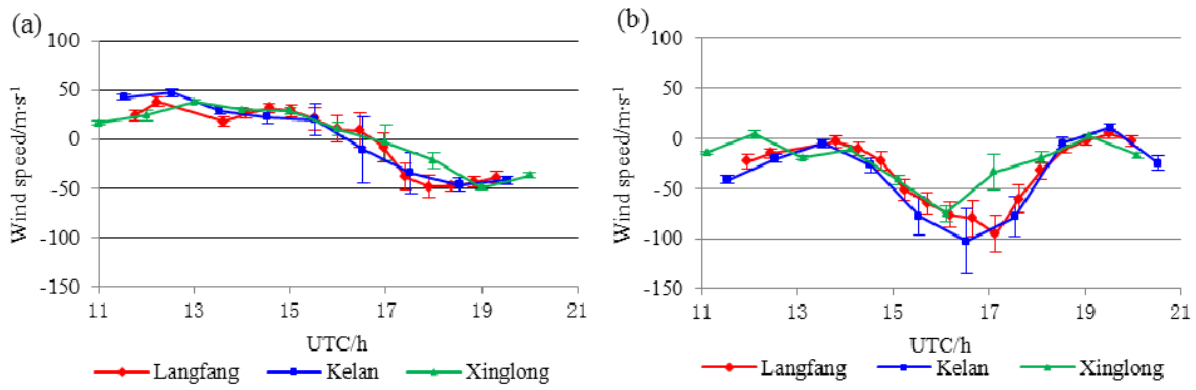

Fig. 3. Zonal (a) and meridional (b) wind retrieval of three FPI instruments on 24 September 2014, as a function of universal time (UTC). The diamond represents wind from our FPI at Langfang site. The square denotes wind results of A-NCAR FPI instrument located at Kelan site. The triangle denotes wind results of A-NCAR FPI instrument located at Xinglong site. The error bar represents twice of the standard error $(1 \sigma)$, which demonstrates wind retrieval uncertainty and signal-to-noise variation. 

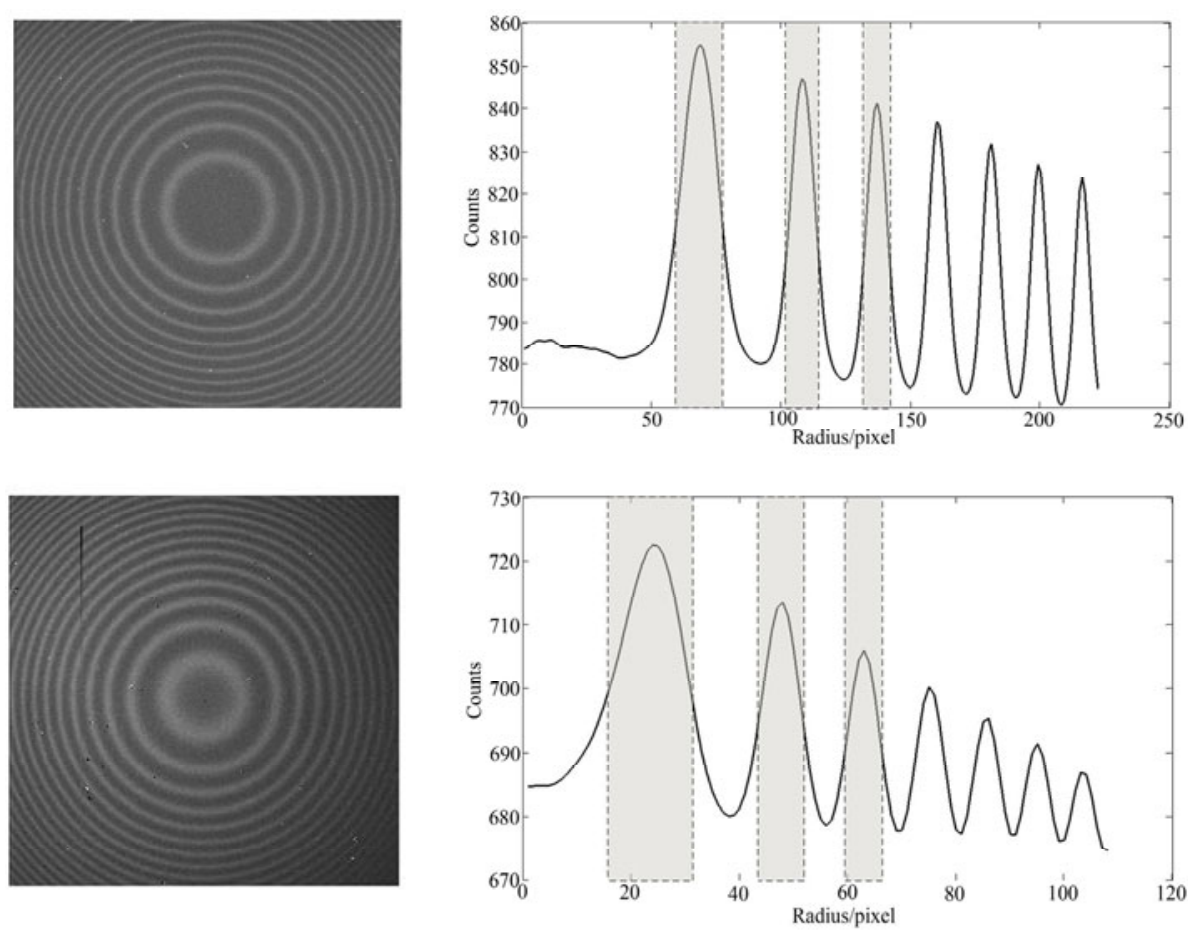

Fig. 4. The interference fringe (left) and annular-summation (right) of the two instruments in the same direction. The upper panel is from our FPI, and the lower panel is from A-NCAR FPI. The curves in gray dashed frame in the right panels indicate the Gaussian functions fitted to the fringes. Seven fringes were all used for the retrieval, but only three fringes used for Gaussian fitting are shown in the gray dashed frames here.

The interference fringes of the same direction of our FPI and A-NCAR FPI are compared and shown in Fig. 4 (left column). A corresponding crosssection of interference fringes is also shown in Fig. 4 (right column) that is a one-dimensional representation after annular-summation. It should be noted that $2 \times 2$ binning of the pixels is done for all the observed data to advance signal-to-noise, while the A-NCAR instrument uses $4 \times 4$ binning. Background count of our FPI ( 780, Fig. 4, upper panel) is a little larger than that of the A-NCAR instrument ( 680, Fig. 4, lower panel). One reason for the phenomenon is that more stray light is reflected in our tiny house. Another is that a little more background emissions from the sky out of the field-of-view enter into our FPI because of city light surrounded the Kelan station. Wind results of five days are compared in Fig. 5. The averaged deviation of wind velocities between the two FPIs is $11.8 \mathrm{~m} / \mathrm{s}$. The averaged measurement er- 

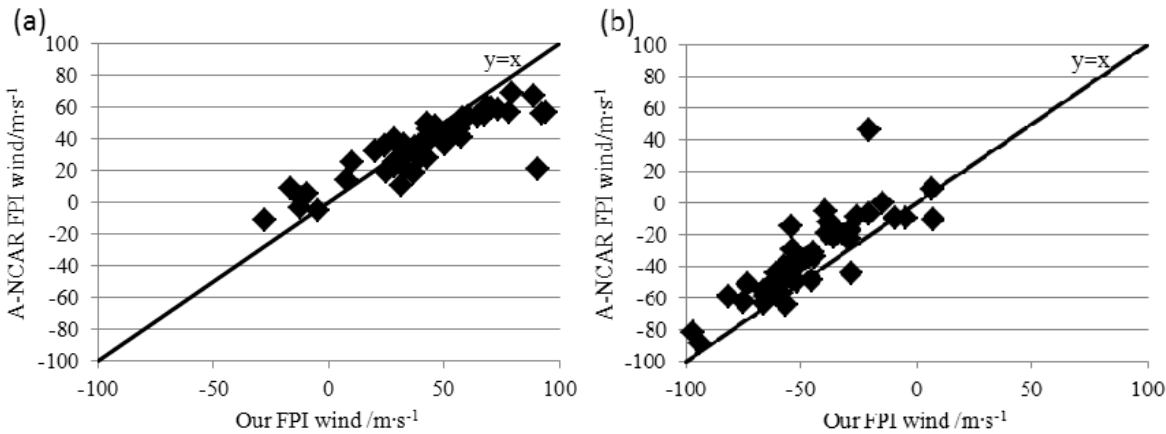

Fig. 5. Zonal (a) and meridional (b) wind of two FPI instruments in Kelan experiment. The black line $(\mathrm{y}=\mathrm{x})$ indicates values one-to-one.

ror of our instrument is $16.4 \mathrm{~m} / \mathrm{s}$, and the averaged measurement error of ANCAR FPI is $13.5 \mathrm{~m} / \mathrm{s}$. It means that the averaged deviation of wind measurement error is $2.9 \mathrm{~m} / \mathrm{s}$ between the two instruments. The comparisons show good agreement except for several large-deviation points which is due to the disturbance of cloud and stray lights (e.g., city-light or lamp-light) in field-of-view.

Figure 6 shows a further comparison of measurements of one night (25 October 2014). It suggests good agreement between them. The average deviation of time-coincident retrievals at this night is $8.60 \mathrm{~m} / \mathrm{s}$. Additionally, the retrieval method used in this paper, different from the A-NCAR retrieval method, is also used for wind retrieval in combination with A-NCAR FPI data. These results called "A-NCAR retrieval" are shown with triangle in Fig. 6.
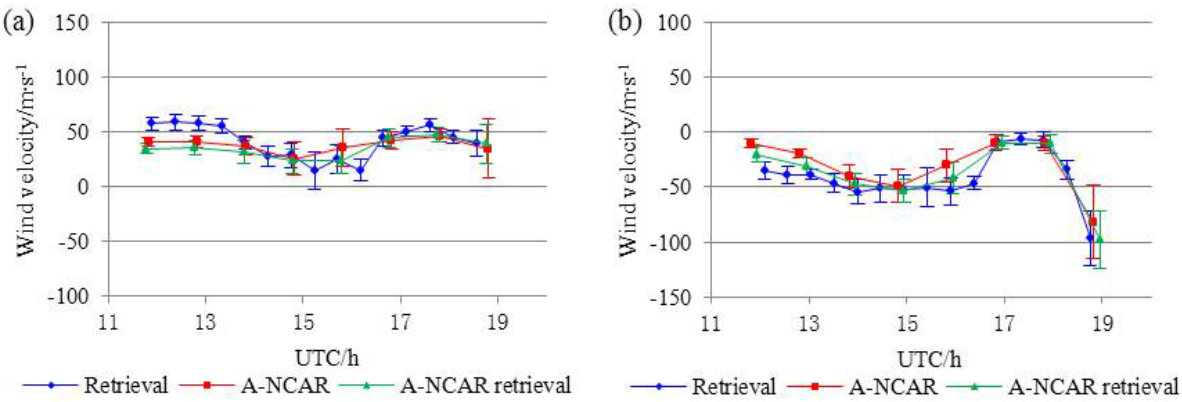

Fig. 6. Zonal (a) and meridional (b) wind retrieval of two FPI instruments as a function of universal time (UTC) on 25 October 2014. The diamond represents wind velocities from FPI. The square denotes wind products of A-NCAR FPI instrument. The triangle represents wind results of A-NCAR FPI data using our retrieval method. 


\section{ANALYSIS AND DISCUSSION}

The precision of wind retrieval mainly depends on the airglow intensity, noise (dark noise and background), and radius fitting, etc. (Wang and Wang 2015). Due to the low intensity of $630.0 \mathrm{~nm}$ airglow, the common retrieval error of a scanning FPI is $4-30 \mathrm{~m} / \mathrm{s}$ for ground-based measurements. The averaged wind measurement error of a FPI fabricated by Boston University is $15 \mathrm{~m} / \mathrm{s}$ (Martinisa et al. 2001). The measurement error of a FPI fabricated by Japanese Nagoya University is $4-27 \mathrm{~m} / \mathrm{s}$ (Shiokawa et al. 2012), and the measurement error of A-NCAR FPI is $6-10 \mathrm{~m} / \mathrm{s}$ (Wu et al. 2004, Yu et al. 2014). The retrieval error of our FPI for $630.0 \mathrm{~nm}$ airglow is $4-20 \mathrm{~m} / \mathrm{s}$. Besides, the lower intensity of $630.0 \mathrm{~nm}$ airglow during 14:00-17:00 UTC (with large error bars) leads to larger uncertainties of wind velocities, which will enlarge the wind deviation between them. Therefore, the deviation of $11.8 \mathrm{~m} / \mathrm{s}$ between our FPI and A-NCAR FPI demonstrates that the wind results of the two instruments are well consistent with each other.

The main factors (airglow intensity, instrument noise, and background emissions, etc.) work on precision of wind measurements according to two main parameters which are calculated during wind retrieval. One is the fringe center, and another is the fringe radius.

\subsection{Center determination}

When the wind velocities retrieved from two FPI instruments in Kelan (our FPI and A-NCAR FPI) are nearly equal with each other, the averaged wind is considered as the real wind. The offset of the center corresponding to real wind is set to zero. Then, center offsets in 8 azimuthal directions $\left(45^{\circ}-360^{\circ}\right.$, step $=45^{\circ}$ ) are carried out, and corresponding wind deviation is calculated simultaneously for each center offset. Based on the method, we obtained several groups of wind deviation versus center offset. The averaged result is shown in Fig. 7a. The relationship between them is an exponential curve which shows that 2 pixels center offset can lead to $4.3 \mathrm{~m} / \mathrm{s}$ wind deviation and that 6 pixels offset causes a much larger wind deviation: $114 \mathrm{~m} / \mathrm{s}$. When the center offset is 7 pixels, wind deviation is up to several thousand meters per second. Therefore, for our FPI instrument and retrieval method, the offset of center determination should be within 2 pixels which can ensure enough accuracy for wind retrieval of thermospheric atmosphere.

\subsection{Radius calculation}

With the same analysis method as the influence of center offset on wind deviation, the influence of radius offset on the wind retrieval is made (Fig. 7b). The relationship between radius offset and wind deviation is linear, with a 

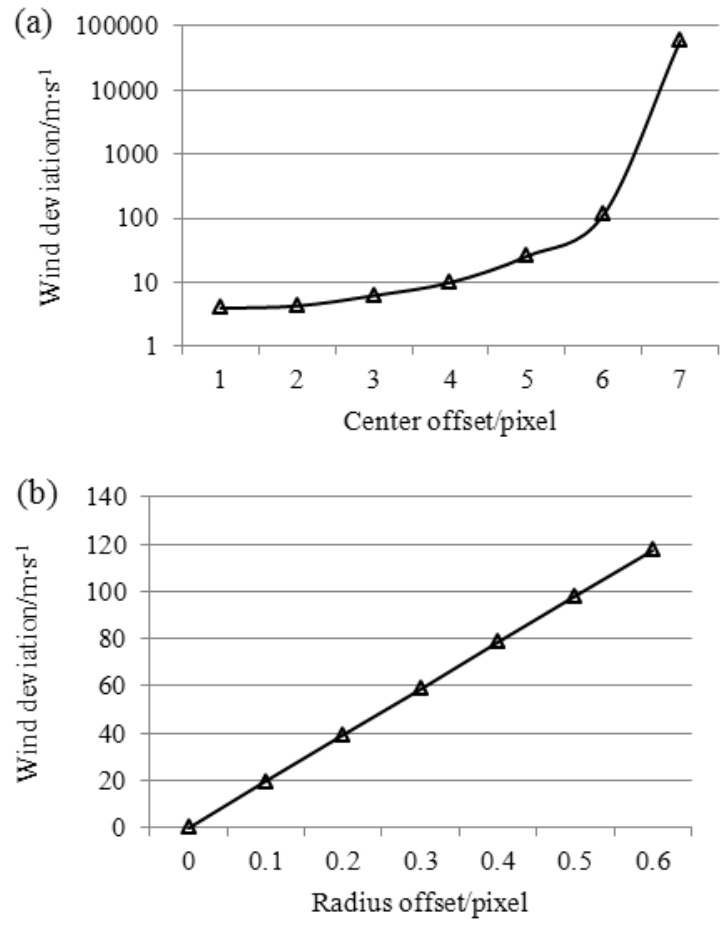

Fig. 7. The wind deviation caused by offsets of center determination (a) and radius calculation (b). The step of center offset is 1 pixel, and the step of radius offset is 0.1 pixels.

slope 19.7, which suggests that radius offsets of 0.1 pixels will cause a wind deviation of $19.7 \mathrm{~m} / \mathrm{s}$.

\section{CONCLUSION}

We successfully performed measurements of airglow with a tiny groundbased FPI with a band-pass filter behind etalon and Galilean telescope system. The main purpose of these experiments was to provide an independent ground-based validation of our FPI including FPI operation, detection capability, data processing method, and the retrieval precision. The observations are performed at Langfang site for a rough validation and subsequently at Kelan site for a detailed comparison with A-NCAR FPI measurements. At Langfang site, the variable trends of wind measurement of our FPI are consistent with that of A-NCAR FPI. At Kelan site, the averaged deviation of wind measurements between our FPI and A-NCAR FPI is $11.8 \mathrm{~m} / \mathrm{s}$, and the averaged deviation of wind measurement error between the two instruments is $2.9 \mathrm{~m} / \mathrm{s}$. The comparisons of the inferred zonal and meridional wind velocities show good agreement with each other.

Based on experiments, influencing factors of wind retrieval of our FPI are analyzed. One is center determination, and another is radius calculation. 
The offset of the former one has an exponential relation with wind deviation. The center offset of 2 pixels can lead to $4.3 \mathrm{~m} / \mathrm{s}$ wind deviation, while the center offset of 7 pixels will cause a much larger wind deviation which is up to several thousand meters per second. The offset of the latter one is linear with deviation of wind retrieval. The radius offsets of 0.1 pixels can cause a wind deviation of $19.7 \mathrm{~m} / \mathrm{s}$. Therefore, the precision of wind retrieval is much more sensitive to radius calculation than center determination.

Acknowledgments. Work about the wind observation experiment was supported by Langfang and Kelan observation stations. Thank to them for supplying places and observation conditions. Work about the comparison of FPI wind retrieval was supported by National Satellite Meteorological Center and State Key Laboratory of Space Weather (China). The authors would like to thank all of them for their outstanding support.

\section{References}

Biondi, M.A., D.P. Sipler, M.E. Zipf, and J.L. Baumgardner (1995), All-sky Doppler interferometer for thermospheric dynamics studies, Appl. Opt. 34, 10, 1646-1654, DOI: 10.1364/AO.34.001646.

Biondi, M.A., S.Y. Sazykin, B.G. Fejer, J.W. Meriwether, and C.G. Fesen (1999), Equatorial and low latitude thermospheric winds: Measured quiet time variations with season and solar flux from 1980 to 1990, J. Geophys. Res. 104, A8, 17091-17106, DOI: 10.1029/1999JA900174.

Conde, M., J.D. Craven, T. Immel, E. Hoch, H. Stenbaek-Nielsen, T. Hallinan, R.W. Smith, J. Olson, Wei Sun, L.A. Frank, and J. Sigwarth (2001), Assimilated observations of thermospheric winds, the aurora, and ionospheric currents over Alaska, J. Geophys. Res. 106, A6, 10493-10508, DOI: 10.1029/2000JA000135.

Gerrard, A.J., and J.W. Meriwether (2011), Initial daytime and nighttime SOFDI observations of thermospheric winds from Fabry-Perot Doppler shift measurements of the 630-nm OI line-shape profile, Ann. Geophys. 29, 9, 15291536, DOI: 10.5194/angeo-29-1529-2011.

Hernandez, G., and R.G. Roble (1995), Thermospheric nighttime neutral temperature and winds over Fritz Peak Observatory: Observed and calculated solar cycle variation, J. Geophys. Res. 100, A8, 14647-14659, DOI: 10.1029/ 95JA00565.

Ishii, M., S. Okano, E. Sagawa, S. Watari, H. Mori, I. Iwamoto, and Y. Murayama (1997), Development of Fabry-Perot interferometers for airglow observations, Proc. NIPR Symp. Upper Atmos. Phys. 10, 97-108. 
Kosch, M.J., C. Anderson, R.A. Makarevich, B.A. Carter, R.A.D. Fiori, M. Conde, P.L. Dyson, and T. Davies (2010), First E region observations of mesoscale neutral wind interaction with auroral arcs, J. Geophys. Res. 115, A2, A02303, DOI: 10.1029/2009JA014697.

Kubota, M. (1996), A study on middle-scale variations of thermospheric neutral winds associated with auroral activity over Syowa Station, Antarcica, Tohoku University, Japan.

Makela, J.J., J.W. Meriwether, J.P. Lima, E.S. Miller, and S.J. Armstrong (2009), The remote equatorial nighttime observatory of ionospheric regions project and the International Heliospherical Year, Earth Moon Planet 104, 1, 211226, DOI: 10.1007/s11038-008-9289-0.

Makela, J.J., J.W. Meriwether, Y. Huang, and P.J. Sherwood (2011), Simulation and analysis of a multi-order imaging Fabry-Perot interferometer for the study of thermospheric winds and temperatures, Appl. Opt. 50, 22, 4403-4416, DOI: $10.1364 /$ AO.50.004403.

Martinisa, C., J. Meriwether, R. Niciejewski, M. Biondi, C. Fesen, and M. Mendillo (2001), Zonal neutral winds at equatorial and low latitudes, J. Atmos. SolarTerr. Phys. 63, 14, 1559-1569, DOI: 10.1016/S1364-6826(01)00022-0.

Meriwether, J.W., J.J. Makela, Y. Huang, D.J. Fisher, R.A. Buriti, A.F. Medeiros, and H. Takahashi (2011), Climatology of the nighttime equatorial thermospheric winds and temperatures over Brazil near solar minimum, J. Geophys. Res. 116, A4, A04322, DOI: 10.1029/2011JA016477.

Nakajima, H., S. Okano, H. Fukunishi, and T. Ono (1995), Observations of thermospheric wind velocities and temperatures by the use of a Fabry-Perot Doppler imaging system at Syowa Station, Antarctica, Appl. Opt. 34, 36, 8382-8395, DOI: 10.1364/AO.34.008382.

NASA (2009), Heliophysics: the solar and space physics of a new era, Heliophysics Roadmap Team, NASA Advisory Council.

Niciejewski, R., T.L. Killeen, and M. Turnbull (1994), Ground-based Fabry-Perot interferometry of the terrestrial nightglow with a bare charge-coupled device: remote field site deployment, Opt. Eng. 33, 2, 457-465, DOI: 10.1117/ 12.155931 .

Rees, D., A.H. Greenaway, R. Gordon, I. McWhirter, P.J. Charleton, and A. Steen (1984), The Doppler imaging system: Initial observations of the auroral thermosphere, Planet. Space Sci. 32, 3, 273-285, DOI: 10.1016/00320633(84)90163-6.

Sakanoi, T., H. Fukunishi, K. Igarashi, S. Okano, and N. Nishitani (2009), Neutralion interaction in the auroral $\mathrm{E}$ region obtained from coordinated FabryPerot imager and VHF radar observations, J. Geophys. Res. 114, A9, A09305, DOI: 10.1029/2008JA013956.

Shiokawa, K., T. Kadota, M. K. Ejiri, Y. Otsuka, Y. Katoh, M. Satoh, and T. Ogawa (2001), Three-channel imaging Fabry-Perot interferometer for measure- 
ment of mid-latitude airglow, Appl. Opt. 40, 24, 4286-4296, DOI: 10.1364/ AO.40.004286.

Shiokawa, K., T. Kadota, Y Otsuka, T. Ogawa, T. Nakamura, and S. Fukao (2003), A two-channel Fabry-Perot interferometer with thermoelectric-cooled CCD detectors for neutral wind measurement in the upper atmosphere, Earth Planets Space 55, 5, 271-275, DOI: 10.1186/BF03351759.

Shiokawa, K., Y. Otsuka, S. Oyama, S. Nozawa, M. Satoh, Y. Katoh, Y. Hamaguchi, and Y. Yamamoto (2012), Development of low-cost sky-scanning Fabry-Perot interferometer for airglow and auroral stydies, Earth Planet. Space 64, 11, 1033-1046, DOI: 10.5047/eps.2012.05.004.

Smith, R.W. (1998), Vertical winds: A tutorial, J. Atmos. Terr. Phys. 60, 14, $1425-$ 1434, DOI: 10.1016/S1364-6826(98)00058-3.

Wang, H., and Y. Wang (2015), Error calculation and analysis for an improved wind retrieval method based on the ground-based Fabry-Perot interferometer measurements, Adv. Space Res. 56, 9, 1815-1821, DOI: 10.1016/j.asr.2015. 03.010 .

Wu, Q., R.D. Gablehouse, S.C. Solomon, T.L. Killeen, and C.-Y. She (2004), A new Fabry-Perot interferometer for upper atmosphere research, Proc. SPIE 5660, 218-227, DOI: 10.1117/12.573084.

Wu, Q., W. Wang, and R.G. Roble, I. Häggström, and A. Strømme (2012), First daytime thermospheric wind observation from a balloon-borne Fabry-Perot interferometer over Kiruna (68N), Geophys. Res. Lett. 39, 14, L14104, DOI: $10.1029 / 2012$ GL052533.

Yu, T., C. Huang, G. Zhao, T. Mao, Y. Wang, Z. Zeng, J. Wang, and C. Xia (2014), A preliminary study of thermosphere and mesosphere wind observed by Fabry-Perot over Center China, J. Geophys. Res. 119, 6, 4981-4997, DOI: 10.1002/2013JA019492.

Received 29 March 2015

Received in revised form 23 October 2015

Accepted 21 March 2016 